\title{
Quantity and quality components of effectiveness in insular pollinator assemblages
}

\author{
María C. Rodríguez-Rodríguez • Pedro Jordano • \\ Alfredo Valido
}

\begin{abstract}
Ecologically isolated habitats (e.g., oceanic islands) favor the appearance of small assemblages of pollinators, generally characterized by highly contrasted life modes (e.g., birds, lizards), and opportunistic nectarfeeding behavior. Different life modes should promote a low functional equivalence among pollinators, while opportunistic nectar feeding would lead to reduced and unpredictable pollination effectiveness (PE) compared to more specialized nectarivores. Dissecting the quantity (QNC) and quality (QLC) components of PE, we studied the opportunistic bird-lizard pollinator assemblage of Isoplexis canariensis from the Canary Islands to experimentally evaluate these potential characteristics. Birds and lizards showed different positions in the PE landscape, highlighting their low functional equivalence. Birds were more efficient than lizards due to higher visitation frequency (QNC). Adult lizards differed from juveniles in effecting a higher production of viable seeds (QLC). The disparate life modes of birds and lizards resulted in ample intra- and inter-specific PE variance. The main sources of $\mathrm{PE}$ variance were visitation frequency (both lizards and birds), number of flowers probed (lizards) and proportion of viable seeds resulting from a single visit (birds). The non-coincident locations of birds and lizards on the PE
\end{abstract}

Communicated by Steven Johnson.

Electronic supplementary material The online version of this article (doi:10.1007/s00442-013-2606-y) contains supplementary material, which is available to authorized users.

M. C. Rodríguez-Rodríguez (\&) · P. Jordano · A. Valido Integrative Ecology Group, Estación Biológica de Doñana (EBD-CSIC), C/Américo Vespucio s/n, 41092 Isla de la Cartuja, Sevilla, Spain

e-mail: canderguez@ebd.csic.es landscape indicate potential constraints for effectiveness. Variations in pollinator abundance can result in major effectiveness shifts only if QLC is relatively high, while changes in QLC would increase PE substantially only at high QNC. The low functional equivalence of impoverished, highly contrasted pollinator assemblages may be an early diagnostic signal for pollinator extinction potentially driving the collapse of mutualistic services.

Keywords Bird pollination - Canary Islands · Lizard pollination · Opportunistic nectar-feeding · Plant reproductive biology

\section{Introduction}

The biotically mediated transfer of pollen grains is performed by diverse animals that differ in their performance across and within species (Schemske and Horvitz 1984; Larsson 2005; Vázquez et al. 2005). This mutualistic service is generally quantified in terms of pollination effectiveness (PE), the product of the frequency of pollen transfer (quantity component, QNC), and the efficiency of this transfer with respect to plant reproductive success (quality component, QLC) (Stebbins 1970; Primack and Silander 1975; Herrera 1987, 1989; Ne'eman et al. 2010; for other mutualistic systems see also Schupp 1993; Ness et al. 2006; Schupp et al. 2010). While QNC frequently reflects variation in visitation frequency to plants (and flowers) across mutualists, QLC implies variation in their net effect via male and female plant fitness. However, both components are not necessarily correlated. The most abundant pollinator may or may not be the one that transfers the greatest amount of pollen (Schemske and Horvitz 1984; Waser and Price 1990; Mayfield et al. 2001). 
Hence, unexpected visitors can be surprisingly effective pollinators (e.g., insects visiting "bird-pollinated" flowers; Vaughton 1992; Mayfield et al. 2001).

The estimation of QNC and QLC is crucial for understanding the ecological and evolutionary patterns of functional equivalence in pollinator assemblages and their underlying factors (Zamora 2000). The outcomes of both effectiveness components are influenced by the speciesspecific traits of the interacting species (e.g., flower morphology, pollinator body size), and by the biotic (e.g., pollinator species richness) and abiotic context (e.g., climatic conditions). A robust PE estimation requires disentangling the multiplicative effects of QNC and QLC, and their relative contributions. These effects ultimately define the positions of each pollinator on the overall PE landscape characteristic of a plant species (sensu Schupp et al. 2010).

One would expect highly dynamic PE landscapes, since pollinator assemblages vary widely in species richness, taxonomic composition and level of functional equivalence among geographic regions, populations and individual plants within a population (Feinsinger et al. 1982; Herrera 1988; Gómez et al. 2007). Multispecific pollinator assemblages would have a greater resilience against negative impacts (e.g., pollinator extinction) than depauperate ones since these species-rich assemblages may favor pollinators which share similar functionality (sensu Armbruster et al. 2000). In contrast, impoverished assemblages with species having functionally disparate traits, or even those formed by a single species, would unlikely withstand these disturbances. If the few species present are not equivalent in effectiveness, consequences will be more severe (Waser et al. 1996; Zamora 2000; Jordano et al. 2003).

Extreme ecological isolation, as found in severely fragmented habitats, high mountain areas and specially in oceanic islands, promotes disharmonic pollinator assemblages (i.e., over- and under-representation of certain taxa) with lower species richness relative to the regional species pool (Inoue 1993; Delgado-García 2000; Olesen and Jordano 2002). Reduced pollinator richness may limit the overall PE received by plants and the variance of effects among and within pollinator species. In fact, a lower QNC (e.g., reduced visitation rate, time spent on the plants and number of flowers contacted per visit; Spears 1987; Inoue 1993), and QLC of effectiveness (e.g., shorter distances of pollen transfer and reduced seed set; Linhart and Feinsinger 1980; Spears 1987) have been reported for insular floras (but see e.g., Schueller 2004). Depauperate pollinator faunas also reduce the possibilities for insular plants to have multiple highly effective pollinators with equivalent roles. Alterations in the strength of plant-pollinator interactions, or even the extinction of particular insular pollinators, are thus more difficult to compensate for (Cox and Elmqvist 2000; Anderson et al. 2011).
Ecological isolation also favors the appearance of opportunistic animal species that exploit nectar as a novel food resource (hereafter "opportunistic nectar-feeding species”). In oceanic islands, such species form small pollinator assemblages often with highly contrasted life modes (e.g., the disparate physiologies, cognitive and locomotion systems of birds and lizards; Olesen and Valido 2003, 2004; Sazima et al. 2009). The weaker nectar dependence of these opportunistic pollinators should lead, a priori, to reduced QNC and QLC, and increased effectiveness variance, compared to assemblages of more specialized nectarivores.

Here we use an insular pollination system from the Canary Islands to study the functional equivalence of its pollinators through the characterization of its PE landscape (one plant species, one passerine bird species, one lacertid lizard species). We first evaluate experimentally the effectiveness for insular opportunistic nectarivores at both inter- and intra-specific levels. Then, we analyze the PE variance and the relative importance of QNC and QLC in this variance by dissecting both components into proximate variables (or subcomponents). We address the following specific questions:

1. Do pollinator species differ in their quantity (QNC) and quality (QLC) components of effectiveness?

2. How do these potential differences in QNC and QLC determine the level of functional equivalence of the mutualistic system (i.e., how are the pollinator species' effects distributed in the PE landscape)?

3. Which subcomponents are the most important to account for the PE variance found in each pollinator species, and is this relative importance consistent across pollinator species?

Materials and methods

Study species and site

The endemic flora of the Canary Islands, an archipelago located about $95 \mathrm{~km}$ off the northwestern coast of Africa, includes various ornithophilous plant species that receive simultaneous floral visits by opportunistic passerine birds and lacertid lizards (Vogel et al. 1984; Olesen 1985; Valido and Olesen 2010). Among them, we selected the mutualistic interactions of the insular foxglove Isoplexis canariensis (L.) J. W. Loudon (Plantaginaceae, formerly Scrophulariaceae; Stevens 2001) with its two most frequent floral visitors (approximately $90 \%$ of total visits, Rodríguez-Rodríguez and Valido 2008) to estimate their PE: the chiffchaff Phylloscopus canariensis (Hartwig 1886) (Phylloscopidae, formerly Sylviidae; Alström et al. 2006) 
and the lizard Gallotia galloti Oudart (Lacertidae). The three species are endemic to the Canary Islands (see illustrations in Online Resource 1).

I. canariensis is a perennial shrub mainly found in the open areas of the laurel forest (500-1,000 m a.s.l). This self-compatible species has typical ornithophilous flowers, with large $(28.0 \pm 2.4 \mathrm{~mm}$ long and $22.6 \pm 2.7 \mathrm{~mm}$ wide, $\mathrm{n}=40$ ), orange, bilabiate corollas which are relatively long-lasting (13.7 \pm 2.7 days; Ollerton et al. 2009). The floral scent is faint (Olesen 1985). The hermaphroditic and protandrous flowers present four anthers located inside the corolla. The stigma is situated between the inferior anthers. Each flower contains nearly 100,000 pollen grains per anther ( $\mathrm{n}=430$ anthers from 44 plants; unpublished data), and several hundred ovules (Ollerton et al. 2009). The nectar is copiously produced (24.8 11 flower $^{-1}$ ), and with a dilute (range: $10-29.5 \%$ of sugar concentration) and relatively hexose-rich composition (sucrose content \33\%) compared to that of insect-pollinated flowers (Vogel et al. 1984; Olesen 1985; Dupont et al. 2004; Ollerton et al. 2009). The nectar tastes bitter to humans, indicating the presence of secondary compounds (Ollerton et al. 2009). Along with birds and lizards, these flowers are also visited by solitary pollen-collecting bees and ants for nectar, but only vertebrates act as legitimate pollinators (RodríguezRodríguez and Valido 2008; present study).

P. canariensis is a small passerine bird (10 $\mathrm{cm}$ length) present in all insular habitats, being extremely abundant in the laurel forest. It mainly feeds on insects and less frequently on fruit pulp. Its diet is supplemented with nectar from both native (up to 13 spp.) and several introduced plant species (e.g., Vogel et al. 1984; Valido and Olesen 2010). G. galloti is a diurnal, medium-size lizard (up to $145 \mathrm{~mm}$ maximum snout-vent length) relatively scarce in the forest habitats, inhabiting border and open areas. This lacertid includes large proportions of plant material in its omnivorous diet (e.g., fleshy fruits, Valido and Nogales 1994, 2003), but also visits flowers for nectar from several native and introduced plant species (e.g., Valido and Olesen 2010). Adults are clearly distinguishable from juveniles by their larger body size and darker coloration pattern.

Our study was conducted at the protected area of Teno Rural Park in north-west Tenerife (Canary Islands, Spain), one of the oldest geological sectors of the island (5.6-6.2 million years, Guillou et al. 2004). The climate is Mediterranean, with a total annual precipitation up to $690 \mathrm{~mm}$ and mean temperature of $14{ }^{\circ} \mathrm{C}$ (Bañares et al. 1991). The predominant vegetation is the Tertiary relict laurel forest (Santos 1990). We selected two distant populations of I. canariensis separated by approximately $4 \mathrm{~km}$ : Teno Alto (870 m a.s.l) and Monte del Agua (700 m a.s.l). The study encompassed the flowering and fruiting periods (May-
September) during 3 consecutive years (study of QNC in 2006 and 2008, and of QLC in 2009).

\section{Quantity component of pollination effectiveness}

In order to characterize the PE, we quantified QNC and QLC by several subcomponents that were estimated at the interspecific (P. canariensis and G. galloti) and intraspecific level (adults and juveniles of G. galloti). The QNC was defined as the product of two subcomponents, visitation rate per $30 \mathrm{~min}$ per plant and the number of flowers probed per plant visit, so QNC $=$ number of visits $30-\mathrm{min}^{-1}$ plant $^{-1} 9$ number of flowers plant ${ }^{-1}$ visit $^{-1}$. This product measures the frequency of discrete mutualistic events (pollinator-flower interaction) measured as the number of flowers probed per unit time. Quantitative data for both subcomponents were obtained during focal observations conducted on 169 adult plants of I. canariensis in two different years (2006, $n=50$ plants; 2008, $n=119$ ). Each individual plant was watched for a minimum of $12.5 \mathrm{~h}$ (up to $135.5 \mathrm{~h}$ ) from 0700 to 2130 hours, yielding a total of $982 \mathrm{~h}$ of observation. Plants were observed at a distance of approximately 7-10 m, with the observer camouflaged by the surrounding vegetation and equipped with binoculars. In 2008 , in order to account for variation in floral display as an offset variable, the total number of open flowers per plant was also recorded for each individual visit.

\section{Quality component of pollination effectiveness}

The QLC was estimated from three subcomponents: the proportion of pollen grains removed per anther per floral visit, added to the product of fruit set per floral visit and the proportion of viable seeds produced per fruit per floral visit. Thus, $\mathrm{QLC}=$ (proportion grains removed anther $^{-1}$ visit $^{-1}$ ) ? (fruit set visit ${ }^{-1} \mathbf{9}$ proportion viable seeds fruit $^{-1}$ visit $^{-1}$ ). This estimate incorporates the joint potential effect of pollen grain removal and seed set (through pollen deposition) following a single probe. The rationale is as follows: the resulting dimensionless QLC is a per flower visit weighting factor for the QNC that explicitly incorporates the effects on both male (pollen removal) and female (fruit and viable seed set) plant reproductive success. QLC can be taken as a probabilistic estimate for the interaction resulting in both successful pollen removal and seed set. These effects act as surrogates of the potential viable seeds produced both on conspecific individuals through successful pollen transfer (male fitness) and/or on the same plant (female plant fitness). For the estimation of the quality subcomponents, we selected a total of 73 plants in 2009 in which individual flowers were excluded to allow only one visit per flower per pollinator group. Plants of similar size and number of inflorescences were selected, and focal 
flowers in the same position in the flowering sequence, to avoid underestimating pollinator performance due to limited maternal resources. In each plant, we labeled two inflorescences, one to estimate pollen removal and the other for fruit set and production of viable seeds per fruit. Each inflorescence was excluded with a simultaneous combination of a chicken-wire cage (25925940 cm) covered with bridal veil (pore diameter $0.25 \mathrm{~mm}$ ) to prevent floral visitors (vertebrates and invertebrates), and ten basal flowers per inflorescence were tagged.

For the estimation of pollen removal, tagged flowers were not manipulated. Before each monitoring period, we visually checked that anthers were recently opened. If there were signals of pollen which had dropped off (e.g., caused by strong wind), the flower was discarded. After a single floral visit by a bird or lizard, we collected all the opened anthers ( $n=347)$ from the visited flower (from one to four opened depending on the floral phenological stage, average $=3.1$ ) with microsurgical scissors and placed them together in the same vial (microcentrifuge tube) to avoid pollen loss from manipulation. We then filled the vial with a standard volume of $70 \%$ ethanol $(1 \mathrm{ml})$. For each oncevisited flower we collected ten undehisced anthers (one anther per flower) from flowers positioned in the lower half of the same inflorescence as a control to estimate the initial number of pollen grains per anther (e.g., Castellanos et al. 2003). These control anthers $(n=430)$ were also placed in independent vials (one anther per vial) filled with $1 \mathrm{ml}$ of $70 \%$ ethanol. We counted the pollen grains (using average values per anther) in the visited and non-visited anthers with an electronic counter (model Z2 cell and particle counter; Beckman Coulter). If there was more than one open anther in the single visited flower in the same vial, the estimated number of pollen grains present was divided by the total number of anthers. For both unvisited and visited anthers, the samples were diluted in $50 \mathrm{ml}$ of Isoton II diluent (Beckman Coulter). Five replicates were obtained for each sample. The mean number of removed pollen grains per anther (no. grains removed anther ${ }^{-1}$ visit $^{-1}$ ) was obtained as the difference between the estimated number of pollen grains in an unvisited anther from the control flower (no. grains unvisited anther ${ }^{-1}, \mathrm{n}=10$ anthers) minus the estimated number of pollen grains remaining in the visited anther from the single-visited flower (no. grains visited anther $^{-1}$ visit $^{-1}$ ). To estimate this difference, we used average values from visited and unvisited flowers within the same inflorescence. After this, we calculated for each pollinator group the proportion of pollen grains removed per anther per floral visit as the proportion grains remove$\mathrm{d}_{\text {anther }}{ }^{-1}$ visit $^{-1}=$ no. grains removed anther ${ }^{-1}$ visit $^{-1} /$ no. grains unvisited anther ${ }^{-1}$.

To estimate the production of fruits and viable seeds per fruit, we left all anthers intact on the first three basal flowers from the tagged inflorescence. We did this to increase the probability of the floral visitor to deposit pollen grains on the manipulated flowers. The following ten basal flowers were tagged and emasculated for single visits. Emasculation assured that all pollen grains deposited on a stigma came from pollinator action, not from the plant's own anthers. After a single visit, we marked and re-bagged the flower, to record later if the flower wilted without fruit production (null fruit set per floral visit, fruit set visit ${ }^{-1}=0$ ) or a fruit ripened (successful fruit set, fruit set visit ${ }^{-1}=1$ ). Ripe fruits were collected to quantify the total number of seeds per fruit per floral visit and the proportion of those that were viable (proportion viable seeds fruit ${ }^{-1}$ visit $^{-1}$ ). Seed viability was determined following the protocol in RodríguezRodríguez and Valido (2008).

Independently of the treatment (male or female plant fitness), all inflorescences were excluded before anthesis until there was at least one flower with open anthers or receptive stigma. During the observations (30-min periods), we monitored from three to four plants simultaneously at a distance of $7-10 \mathrm{~m}$. We removed the cages from only those inflorescences with flowers ready for the treatment (open anthers or receptive stigma). If a flower received a visit, we recorded the pollinator identity and manipulated the flower immediately after the pollinator visit according to the treatment (estimate of male or female plant fitness). At the end of the 30-min period, the whole inflorescences were bagged again to prevent further floral visits if there were remaining unvisited flowers and started the 30-min monitoring in a different group of plants. To prevent rat predation, those inflorescences initially tagged that produced fruits remained caged after blooming.

\section{Pollination effectiveness}

Once QNC and QLC were quantified, we estimated the PE of P. canariensis and G. galloti (overall and for adults and juveniles separately) as the frequency of the flower-pollinator interaction (QNC) weighted by their per flower effect (QLC). Thus, PE = QNC 9 QLC. This definition was used later to represent the $\mathrm{PE}$ landscape and evaluate the relative importance of the five subcomponents on the observed PE variance (see “Statistical analyses”).

\section{Statistical analyses}

All analyses were carried out with $\mathrm{R}$ software version 2.13.0 (R Development Core Team 2011). Although the data for the five PE subcomponents were obtained from plants located in two populations, we pooled all the Isoplexis individuals for analyses. The estimates of the PE subcomponents at the lizard species level (G. galloti) were obtained by combining adult and juvenile observations. 
However, we also included data from six age-undetermined individuals of $\mathrm{G}$. galloti in the subcomponents related to plant female fitness (fruit set per floral visit and the proportion of viable seeds produced per fruit per floral visit) (see Table 1 for sample sizes).

Differences among pollinators for each quantity and quality subcomponent were tested by generalized linear models (GLMs). For the two quantity subcomponents (visitation rate per 30 min per plant and the number of flowers probed per plant visit), we fitted generalized linear mixed models with year as a random factor, negative binomial family and log link function. We then tested the number of flowers probed per plant visit only with 2008 data to cross-check the result, including an offset in the model that scaled this count-type response variable by the number of open flowers per plant in the moment the pollinator visited (see details in Online Resource 2). For the three quality subcomponents (proportion of pollen grains removed per anther per floral visit, fruit set per floral visit and proportion of viable seeds produced per fruit per floral visit) we fitted GLMs at plant and flower sampling unit levels. Results at both levels were identical, so we report only the individual flower-level results. In this case, we used quasi-binomial family and logit link function (further description in Online Resource 2).

From the empirical values obtained for the subcomponents, we estimated PE, its SE and 95 \% bootstrap confidence limits after Reynolds and Fenster (2008), using 100 simulations of mean PE. The simulations were based on bootstrap resamples of the empirical data in order to combine estimates of the QNC and QLC subcomponents obtained in different sets of field observations and experiments. The final PE mean for each pollinator type was obtained as the average across the resampling trials to evaluate the stability of the estimation. As the results were highly consistent among simulations, we randomly selected one of the 100 bootstrap-generated samples to plot the location of each pollinator group on the twodimensional PE landscape. Using the same selected sample, we then evaluated the relative importance of each effectiveness subcomponent in the observed PE variance via multiple regression. We used the metric lmg which decomposes the total model $\mathrm{R}^{2}$ into non-negative partial contributions and then averages the PE subcomponents' effects over models of different sizes and orderings of subcomponents (further description in Online Resource 2).

\section{Results}

Quantity component of pollination effectiveness

Pooling data from 2006 and 2008, we observed a total of 1,363 plant visits, recording the number of probed flowers

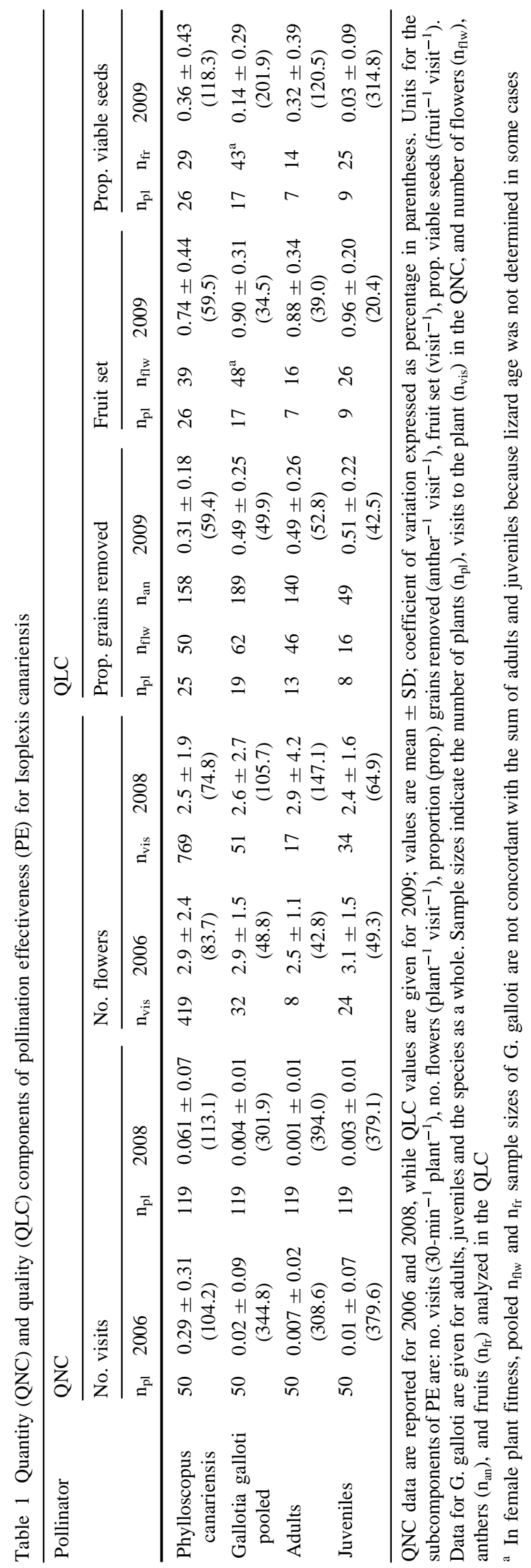


per plant in $[90 \%$ of them ( $\mathrm{n}=1,272$; Table 1$)$. The majority of these visits were performed by Phylloscopus canariensis (93\% of visits, $\mathrm{n}=1273 ; 7 \%$ by Gallotia galloti $n=90$ ). Among lizards, juveniles were the most recorded visitors (juvenile $n=62$, adult $n=28$ ). Thus P. canariensis visited plants with a frequency approximately 13 times higher than that of $\mathrm{G}$. galloti $(|\mathrm{z}|=3.23$, $\mathrm{df}=1, \mathrm{P}=0.001$ ) (Fig. 1a). We did not find any significant differences between age classes when comparing visit rates between adult and juvenile lizards separately from birds $(|z|=1.03$, df $=1, \mathrm{P}=0.54)$ (Fig. 1a).

$P$. canariensis and $G$. galloti did not significantly differ in the number of flowers probed per plant visit $(|z|=0.45$, $\mathrm{df}=1, \mathrm{P}=0.65)$, and neither did Gallotia adults and juveniles ( $|\mathrm{z}|=0.17$, df $=1, \mathrm{P}=0.98$ ) (Fig. 1b). However,

Quantity subcomponents
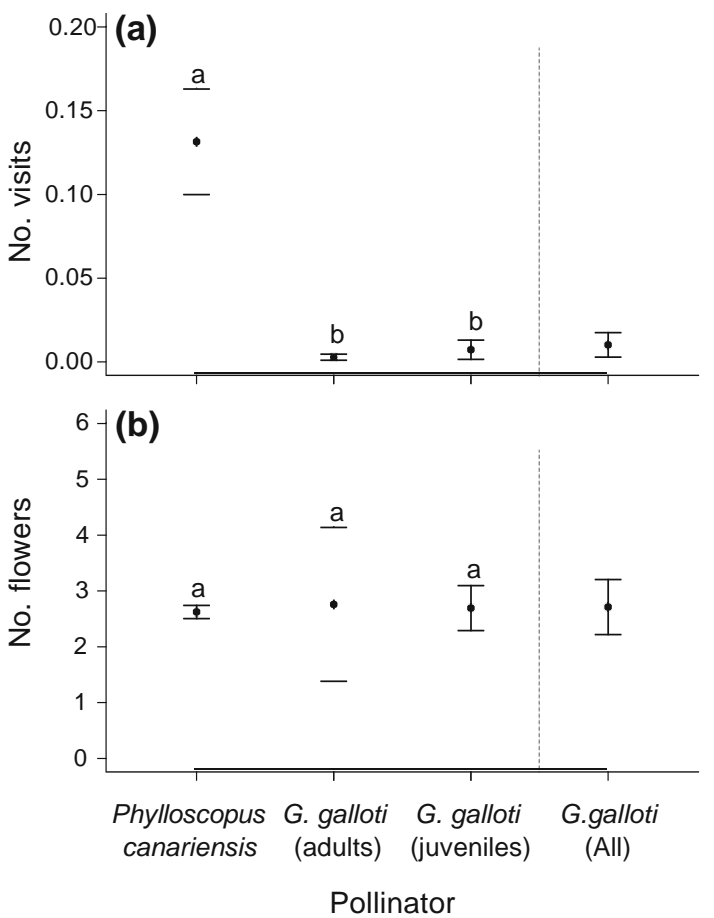

Fig. 1 Quantity and quality subcomponents used to estimate the pollination effectiveness (PE) per pollinator group: a number of visits per 30 min per plant, b number of flowers probed per plant per visit, c proportion of pollen grains removed per anther per floral visit, $\mathrm{d}$ fruit set per floral visit, and e proportion of viable seeds set per fruit if the number of open flowers per plant at the moment of a visit was considered (only 2008 data), differences appeared. On average, plants visited by Gallotia adults had a greater number of open flowers (90.4 \pm 51.5 flowers) than P. canariensis and Gallotia juveniles during the pollinating visit (42.4 \pm 54.9 and $31.6 \pm 30.6$ flowers, respectively). We thus used the floral display as an offset to account for this variation when fitting the GLM. Thus, P. canariensis and Gallotia juveniles visited a higher number of flowers per plant per visit relative to the total number of open flowers compared to the number visited by Gallotia adults ( $\mathrm{P}$. canariensis $|\mathrm{z}|=2.74$, $\mathrm{df}=1, \mathrm{P}=$ 0.015; Gallotia juveniles $|\mathrm{z}|=2.98$, $\mathrm{df}=1, \mathrm{P}=0.007$ ). However, birds and lizard juveniles did not differ $(|z|=1.13$, df $=1, P=0.48)$.
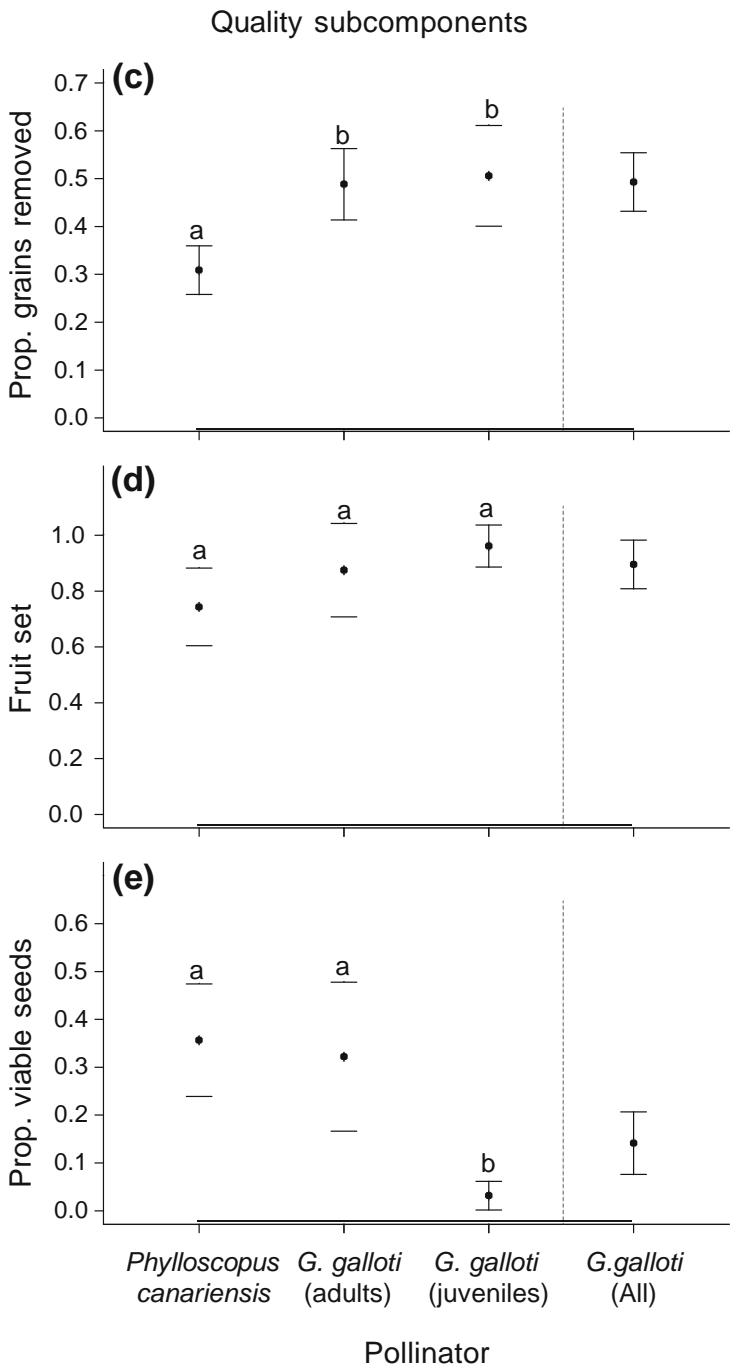

per floral visit. Values are mean $\pm \mathrm{SE}$; for sample sizes, see Table 1 . Different letters indicate statistical differences among pollinators. a, c, e Gallotia galloti (pooled data) and Phylloscopus canariensis differed significantly 
Quality component of pollination effectiveness

For the estimation of pollen removal, a total of 50 flowers were obtained for P. canariensis, and 62 for G. galloti (46 and 16 by adults and juveniles, respectively; Table 1). The proportion of pollen grains removed per anther by birds was 1.6 times lower than that removed by adult $(|z|=3.81$, $\mathrm{df}=1, \mathrm{P} \backslash 0.001)$ and juvenile lizards $(|\mathrm{z}|=3.49, \mathrm{df}=1$, $\mathrm{P}=0.001)$. The two lizard age classes did not differ $(|z|=0.28, \mathrm{df}=1, \mathrm{P}=0.96)$ (Fig. 1c).

For the estimation of fruit set and production of viable seeds per fruit, we obtained data from 39 flowers for P. canariensis, and 48 for G. galloti (16 for adults and 26 for juveniles, undetermined age $n=6$; Table 1 ). The fruit set was high in all pollinator groups ([0.70). Fruit set did not differ between P. canariensis and G. galloti $(|z|=1.78$, $\mathrm{df}=1, \mathrm{P}=0.08)$, or between lizard age classes $(|\mathrm{z}|=$ 0.96, $\mathrm{df}=1, \mathrm{P}=0.60$ ) (Fig. 1d). Flowers visited by P. canariensis produced a proportion of viable seeds per fruit approximately 2.5 times higher than flowers visited by G. galloti $(|z|=2.39, \mathrm{df}=1, \mathrm{P}=0.017$ ) (Fig. 1e). However, the production of viable seeds was similar between P. canariensis and adult lizards $(|z|=0.66$, df $=1$, $\mathrm{P}=0.78$ ), with both groups superior to juvenile lizards $(P \backslash 0.05$; Fig. 1e).

\section{PE estimate and landscape}

The bootstrapped estimates of PE had a high stability across the 100 trials for both vertebrate species: the coefficient of variation for mean, SE, and lower and upper confidence limits for the PE were all less than $3 \%$ (Online Resource 3). By far, P. canariensis was the pollinator with the greatest PE (19.8 $910^{-2}$; Fig. 2), which was 11.5 times higher than that of G. galloti $\left(1.7910^{-2}\right)$ due to a greater QNC. This difference was also maintained when birds were compared separately to Gallotia adults (0.6 $\left.910^{-2}\right)$ and juveniles $\left(1.1910^{-2}\right)$. Within lizards, juveniles showed higher PE than adults (Online Resource 3), although adults were superior in the QLC (Fig. 2).

\section{Relative importance of PE subcomponents}

The partitioning of variance in PE showed significant differences among subcomponents in their relative importance within each pollinator group. All estimated pairwise differences were significant, except between the proportion of pollen grains removed per anther per floral visit and the fruit set per floral visit in P. canariensis (see Online Resource 4 for detailed statistical pairwise tests).

The frequency of visits to plants and flowers, and the proportion of viable seeds per fruit per floral visit were the most important factors in explaining the observed variance

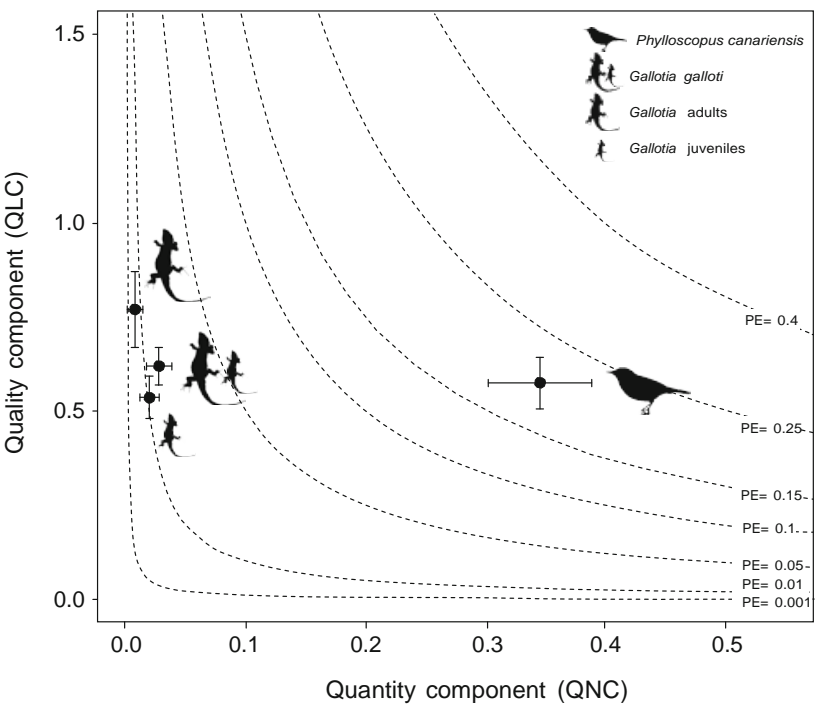

Fig. 2 The PE landscape of Isoplexis canariensis' pollinators. Isoclines represent all combinations of quantity and quality components with the same PE. Values are mean \pm SD

in PE (Г30 \% of variance explained; Fig. 3), but their relative strengths depended on pollinator identity. In P. canariensis, the visitation frequency $(50.8 \%)$ and the proportion of viable seeds (34.6\%) were the major determinants, while for G. galloti the visitation frequency was the dominant factor (89.2 \%; Fig. 3a, b). Considering adult lizards, most of the observed PE variance was explained by the visitation frequency and the number of flowers probed per plant visit (55.5 and $34.9 \%$ respectively), while for juveniles the variance was practically accounted for by the visitation frequency alone (89.9 \%) (Fig. 3c, d).

\section{Discussion}

Our findings show that the PE landscape analyzed in the simple insular assemblage of Isoplexis canariensis was determined by a contrasted combination of their QNC and QLC. Due to the extreme disparity of their pollinator life modes, the opportunistic nectar-feeding passerine Phylloscopus canariensis had a greater PE than the lacertid Gallotia galloti, generating a scenario of extremely low functional equivalence. This difference was largely attributable to variation in QNC. On the other hand, the intraspecific PE differences in the lizard were prompted by QLC, with adults presenting higher quality effectiveness than juveniles. The principal factors increasing the PE variance in this pollinator assemblage were: the visitation rate (birds and lizards), the number of flowers probed per plant visit (lizards), and the proportion of viable seeds produced per flower visit (birds). These factors are directly linked to the local abundance and activity (closely related 
Fig. 3 Relative contribution of the quantity and quality subcomponents to the total variance in PE per pollinator group. Values are mean $\mathrm{lmg}$ estimates $\pm 95 \%$ confidence interval. For statistical pairwise differences among subcomponents, see Online Resource 4

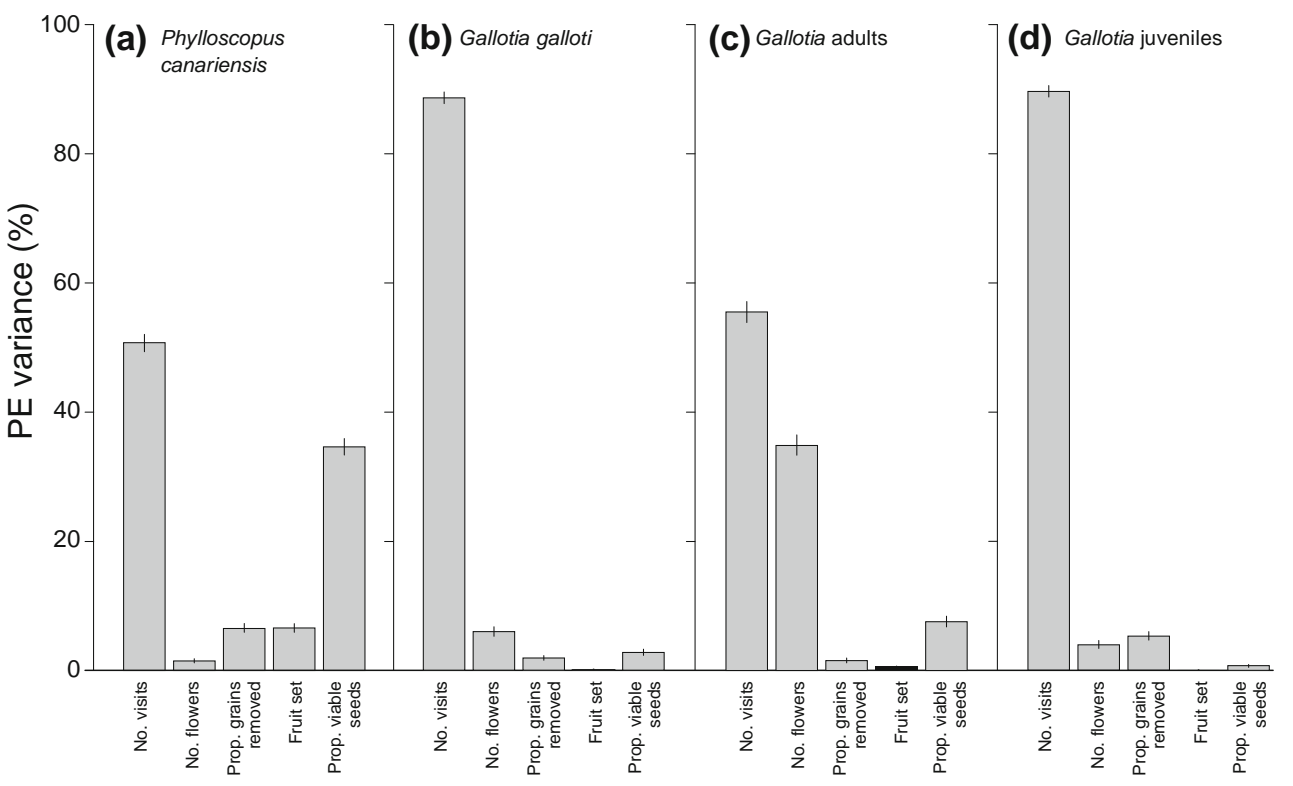

Quantity and quality subcomponents of PE to climatic conditions) in lizards, and to the local densities and movement patterns among/within populations (favoring xenogamous and/or selfing crosses) in birds.

The PE landscape

As expected from the floral traits of I. canariensis, which suggested bird pollination, the passerine P. canariensis was the most effective pollinator. Compared with lizards, birds visited plants with a higher frequency (QNC), and produced fruits with a higher number of viable seeds after a single visit (QLC). These results suggest that the most frequently visiting pollinator species in our system was also the most efficient. Despite these differences, only the QNC was critical in determining the relative positions in the PE landscape of birds and lizards. Birds were approximately 15 times as frequent visitors as lizards in the 2 years studied. As found in other pollination systems, frequently visiting pollinator species usually contribute the most to plant reproduction (e.g., Fishbein and Venable 1996; Vázquez et al. 2005; but see e.g., Vaughton 1992; Mayfield et al. 2001). The observed differences are attributable to their daily activity pattern. While birds are able to visit flowers throughout the day, lizard foraging behavior is largely constrained to the warmest days or hours during the day, although some activity may be recorded in the morning or late evening (Molina-Borja 1985; Valido and Nogales 2003; Rodríguez-Rodríguez and Valido 2008). Previous reports of QNC in other assemblages of pollinators with highly contrasted life modes (mostly insects vs. birds) indicate that frequency of visits is not consistently the most important component in the determination of birds' PE. In some cases, birds were more effective in their quality effectiveness (e.g., Robertson et al. 2005; Fumero-Cabán and Meléndez-Ackerman 2007), while in others in their quantity (Waser and Price 1990; Vaughton 1992; Mayfield et al. 2001). Birds appear to be more effective than ectothermic pollinators (e.g., insects, lizards) when these are scarce (Steenhuisen et al. 2012), in high-elevation habitats (Cruden 1972) or in early flowering periods, when temperatures are usually low and limit the activity of ectotherms (Waser and Price 1990; Vaughton 1992; Valido et al. 2002). Thus, this pattern of greater variation in QNC than in QLC is expected for those pollinator assemblages, such as our study system, with marked inter-specific differences in life modes.

Independently of among-plant variation in floral display, G. galloti adults probed a lower number of flowers per visit compared to juveniles. The explanation for this intra-specific difference remains undetermined. Adult lizards have a lower energy demand compared to juveniles (e.g., Pough 1973). Because of their larger size, adults may have greater accessibility constraints for flower handling, and/or experience greater predation risk that limits their foraging time. But while Gallotia adults probed relatively fewer flowers per visit, their visited flowers produced a higher proportion of viable seeds than flowers visited by juveniles (QLC). This proportion depends on the genetic quality of pollen deposited on the stigma, ultimately determined by the movement pattern of pollinators (e.g., Aizen and Harder 2007). Cross-pollinated I. canariensis flowers produced a greater percentage of viable seeds than self-pollinated ones (Rodríguez-Rodríguez and Valido 2008). Thus, Gallotia juveniles may be effecting poorer pollen transfer than 
adults, with visits resulting more frequently in self-pollination events (autogamy and/or geitonogamy). The quality values obtained were critical to determine the different positions of Gallotia adults and juveniles in the PE landscape, given their similar quantity effect. Variations in QLC are expected to be greater than in QNC when different pollinator species show similar abundances or when we contrast intraspecific groups sharing common life modes (e.g., among sexes, Larsson 2005; Gallotia adults and juveniles).

The resulting PE landscape reflects the low functional equivalence of the system due to the presence of only one highly effective species (P. canariensis). This result is compatible with the high dependence shown by insular plants on pollinators, but not pollinators on plants (Olesen and Jordano 2002). The reproductive output of I. canariensis appears to be more sensitive to changes in the QNC of the pollinator species than to variations in their QLC. For birds, a small increase in the QLC (e.g., greater pollen removal) or QNC (e.g., higher visitation rate) would result in substantial changes in their positions on the PE landscape. The situation for lizards is different: increases in QNC might entail relatively larger increases in PE than variations of QLC. In this way, lizards might reach a closer position to the birds' effectiveness by, e.g., increases in their visitation rate, especially high-quality adults that have a greater morphological floral match and foraging experience than juveniles. Therefore, we suggest that pollinator species of small, disharmonic insular assemblages characterized by opportunistic nectar-feeding behavior can show variable responses in effectiveness, but with some restrictions imposed by the species-specific traits and/or context. Subtle variations in QNC or QLC can result in major changes in PE only if the pollinator has a relatively high value in the other component of effectiveness.

The low equivalence among pollinators of the studied system highlights two important aspects. First, the scarcity of multiple highly effective pollinators may be an early diagnostic signal for the potential collapse of mutualistic services derived from the loss of the most effective pollinator (e.g., Olesen et al. 2007). Second, birds and lizards may play complementary roles for the plant reproductive success, especially when plant populations would be limited by bird activity. The combination of pollinators with high (P. canariensis) and low (G. galloti) PE may thus be considered favorable. The presence of different pollinator feeding behaviors allow a greater pollen dispersal over more habitats than can be reached by only one species or group of similar species within a single functional group (Armbruster et al. 2000; Schupp et al. 2010). The low equivalence revealed in our study contrasts with the higher values reported for multispecific, and more generalized, mainland assemblages (Inoue 1993; Gómez and Zamora
1999; Olesen and Jordano 2002). Empirical measures of overall pollinator services (and not just those of isolated effectiveness components) are needed to identify if such pollinator-impoverished, functionally non-equivalent, assemblages are characteristic of islands, and the ecological conditions that promote them compared to more complex systems.

\section{Relative importance of PE subcomponents}

It is widely recognized that partner species can differ in their effectiveness as pollinators, but the components of this variation have been rarely dissected. When done, substantial variation among visitors has been found in several components of pollinator effectiveness, and many of these components were weakly correlated (e.g., Ivey et al. 2003). The primary source of these differences relies on the underlying variation among individuals of the same group at each PE subcomponent (e.g., variance in visit rate among Gallotia juveniles) that scales up to higher levels (among conspecifics and/or species). Our results on the percentage of PE variance explained demonstrate that three subcomponents of PE have potential compensatory effects for the restricted variation found in the others. Thus, highly variable visitation rate (all pollinators), and to a lesser extent, the number of probed flowers per plant visit (only in Gallotia adults) and the production of viable seeds (only in the passerine $\mathrm{P}$. canariensis) modulate the less variable handling subcomponents (pollen removal and fruit set per floral visit), with slight changes depending on the pollinator identity.

Fluctuations in the quantity and quality of the pollinator assemblage can alter the strength of selection exerted by any pollinator taxon, which suggests that selection strength is markedly context dependent (Aigner 2001; Bronstein et al. 2003). Indeed, generalized and facultative mutualisms (i.e., opportunistic nectar-feeders) are often characterized by ample spatio-temporal variation in effectiveness (Herrera 1988; Ness et al. 2006). The local context may be decisive to determine the higher relative importance frequently found in the visitation frequency (e.g., structure and composition of the surrounding landscape; Tscheulin et al. 2011). We expect the remaining subcomponents, especially those from the QLC, to show a lower variance in nature because they are much more dependent on the species-specific match of pollinator and floral traits than quantity subcomponents. In our system, visitation frequency accounted for most variance in PE across all pollinator groups (C50 \% of importance). The fact that the members of the studied assemblage were opportunistic nectar feeders may have resulted in a greater unpredictability in their visitation frequency compared to their handling capabilities for pollination. As opportunistic birds 
and lizards are not strictly dependent on nectar, the availability of alternative food resources may condition, and potentially limit, their effectiveness as pollinators. For example, high insect or fruit availability (birds and lizards) or fluctuations in ambient temperature (lizards) may cause foraging shifts and result in lower pollinator dependence on nectar sources and thus, in reduced plant visitation.

The production of viable seeds per floral visit (QLC) was unexpectedly important as an explanatory factor for the PE variance in the passerine P. canariensis (see e.g., Vázquez et al. 2005). The spatial context may also influence the movement paths of these pollinators and consequently, the genetic quality of the pollen load carried and the final viable seed set. For example, Abe et al. (2011) have demonstrated greater home range and genetic diversity of pollen loads by the opportunistic nectarivorous white-eye Zosterops japonica Temminck and Schlegel (Zosteropidae) in areas with low flower density, ultimately conditioned by insular volcanic activity. As birds are active throughout the day, they have more possibilities to explore resources and perform daily switches from insects to nectar or vice versa depending on daily cycles of food availability and the presence of other interacting taxa (e.g., floral herbivores). Considering that insular ecological conditions promote the appearance of opportunistic nectar-feeding pollinators, we expect a greater context dependence as a characteristic feature of insular pollinator assemblages, with the mutualistic service ultimately conditioned by the availability of alternative resources.

\section{Conclusion}

Our dissection of the PE landscape in the insular assemblage studied has shown that both quantity and quality components play an important role in determining the positions of the bird-lizard pollinator groups. The bird P. canariensis is the most effective pollinator, yet its effects are complementary to those of the lizard G. galloti, which occupies a rather different location in the PE landscape. Small pollinator assemblages with contrasted life modes and high complementarity are indicative of potential low functional equivalence systems, where the loss of an effective pollinator might collapse the mutualistic service. This renders insular systems particularly sensitive to anthropogenic change, a pressure that will likely increase more markedly on islands than on the mainland in the near future (Kier et al. 2009). It would be thus interesting to explore if this low functional equivalence is a characteristic feature of impoverished, highly disharmonic pollinator assemblages of opportunistic nectarivores from e.g., relatively isolated habitats, in order to focus conservation efforts on these fragile pollination systems.
Acknowledgments The authors thank especially A. M. Rodríguez and D. Rodríguez, R. Pedrianes, M. Carrión and the forest guards of Teno Rural Park for their technical support. The Island Ecology and Biogeography Research Group (La Laguna University), Anna Traveset and the Terrestrial Ecology Group (IMEDEA-CSIC) and the city council of Buenavista del Norte helped with logistics. Sampling permits were granted by the Department of Sustainability, Territory and Environment of the Cabildo Insular de Tenerife. Jens M. Olesen provided us generously with the images of the pollinators $\mathrm{P}$. canariensis and G. galloti visiting the flowers of I. canariensis (Online Resource 1). Comments by Eugene W. Schupp, Steven D. Johnson and two anonymous referees greatly improved the manuscript. The study was supported by a predoctoral fellowship to M. C. R. from the Consejo Superior de Investigaciones Científicas (I3P I3PPRE_06_00019 CSIC), a postdoctoral grant to A. V. from the Ministerio de Ciencia e Innovación (RYC-2007-00620), and funds to P. J. from the Junta de Andalucía (Excellence grants P07-RNM0284, RNM-573). The experiments performed in this study comply with the current Spanish laws.

\section{References}

Abe H, Ueno S, Tsumura Y, Hasegawa M (2011) Expanded home range of pollinator birds facilitates greater pollen flow of Camellia japonica in a forest heavily damaged by volcanic activity. In: Isagi Y, Suyama Y (eds) Single-pollen genotyping. Springer, Tokyo, pp 47-62. doi: 10.1007/978-4-431-53901-8_5

Aigner PA (2001) Optimality modeling and fitness trade-offs: when should plants become pollinator specialists? Oikos 95:177-184. doi:10.1034/j.1600-0706.2001.950121.x

Aizen MA, Harder LD (2007) Expanding the limits of the pollenlimitation concept: effects of pollen quantity and quality. Ecology 88:271-281. doi:10.1890/06-1017

Alström P, Ericson PGP, Olsson U, Sundberg P (2006) Phylogeny and classification of the avian superfamily Sylvioidea. Mol Phylogenet Evol 38:381-397. doi:10.1016/j.ympev.2005.05.015

Anderson SH, Kelly D, Ladley JJ, Molloy S, Terry J (2011) Cascading effects of bird functional extinction reduce pollination and plant density. Science 331:1068-1071. doi:10.1126/science. 1199092

Armbruster WS, Fenster CB, Dudash MR (2000) Pollination “principles" revisited: specialization, pollination syndromes, and the evolution of flowers. Det Norske Videnskapsakademia. I. Matematisk Naturvidenskapelige Klasse, Skrifter 39:139-148

Bañares A, Blanco A, Castroviejo M, Fernández López A, Gandullo JM, Muñoz L, Sánchez Palomares O, Serrada R (1991) Estudio ecológico de la laurisilva canaria. ICONA, Madrid

Bronstein JL, Wilson WG, Morris WF (2003) Ecological dynamics of mutualist/antagonist communities. Am Nat 162:S24-S39. doi: $10.1086 / 378645$

Castellanos MC, Wilson P, Thomson JD (2003) Pollen transfer by hummingbirds and bumblebees, and the divergence of pollination modes in Penstemon. Evolution 57:2742-2752. doi:10.1554/ 03-215

Cox PA, Elmqvist T (2000) Pollinator extinction in the Pacific Islands. Conserv Biol 14:1237-1239. doi:10.1046/j.1523-1739. 2000.00017.x

Cruden RW (1972) Pollinators in high-elevation ecosystems: relative effectiveness of birds and bees. Science 176:1439-1440. doi: 10.1126/science.176.4042.1439

Delgado-García JD (2000) Patterns of insect flower visitation in Lavandula buchii Webb (Lamiaceae), an endemic shrub of 
Tenerife (Canary Islands). J Nat Hist 34:2145-2155. doi:10. 1080/002229300750022376

Dupont YL, Hansen DM, Rasmussen JT, Olesen JM (2004) Evolutionary changes in nectar sugar composition associated with switches between bird and insect pollination: the Canarian birdflower element revisited. Funct Ecol 18:670-676. doi:10.1111/ j.0269-8463.2004.00891.x

Feinsinger P, Wolfe JA, Swarm LA (1982) Island ecology: reduced hummingbird diversity and the pollination biology of plants, Trinidad and Tobago, West Indies. Ecology 63:494-506. doi: 10.2307/1938966

Fishbein M, Venable DL (1996) Diversity and temporal change in the effective pollinators of Asclepias tuberosa. Ecology 77:10611073. doi: $10.2307 / 2265576$

Fumero-Cabán JJ, Meléndez-Ackerman EJ (2007) Relative pollination effectiveness of floral visitors of Pitcairnia angustifolia (Bromeliaceae). Am J Bot 94:419-424. doi:10.3732/ajb.94.3.419

Gómez JM, Zamora R (1999) Generalization vs. specialization in the pollination system of Hormathophylla spinosa (Crucifera). Ecology 80:796-805. doi:10.1890/0012-9658-080-2

Gómez JM, Bosch J, Perfectti F, Fernández J, Abdelaziz M (2007) Pollinator diversity affects plant reproduction and recruitment: the tradeoffs of generalization. Oecologia 153:597-605. doi: 10.1007/s00442-007-0758-3

Guillou H, Carracedo JC, Paris R, Pérèz Torrado JP (2004) Implications for the early shield-stage evolution of Tenerife from K/Ar ages and magnetic stratigraphy. Earth Planet Sci Lett 222:599-614. doi:10.1016/j.epsl.2004.03.012

Herrera CM (1987) Components of pollinator "quality": comparative analysis of a diverse insect assemblage. Oikos 50:79-90. doi: $10.2307 / 3565403$

Herrera CM (1988) Variation in mutualisms: the spatio-temporal mosaic of a pollinator assemblage. Biol J Linn Soc 35:95-125. doi:10.1111/j.1095-8312.1988.tb00461.x

Herrera CM (1989) Pollinator abundance, morphology, and flower visitation rate: analysis of the "quantity" component in a plantpollinator system. Oecologia 80:241-248. doi:10.1007/BF003 80158

Inoue K (1993) Evolution of mutualism in plant-pollinator interactions on islands. J Biosci 18:525-536. doi:10.1007/BF02703084

Ivey CT, Martinez P, Wyatt R (2003) Variation in pollinator effectiveness in swamp milkweed, Asclepias incarnata (Apocynaceae). Am J Bot 90:214-225. doi:10.3732/ajb.90.2.214

Jordano P, Bascompte J, Olesen JM (2003) Invariant properties in coevolutionary networks of plant-animal interactions. Ecol Lett 6:69-81. doi:10.1046/j.1461-0248.2003.00403.x

Kier G, Kreft H, Lee TM, Jetz W, Ibisch PL, Nowicki C, Mutke J, Barthlott W (2009) A global assessment of endemism and species richness across island and mainland regions. Proc Natl Acad Sci USA 106:9322-9327. doi:10.1073/pnas.0810306106

Larsson M (2005) Higher pollinator effectiveness by specialist than generalist flower-visitors of unspecialised Knauita arvensis (Dipsacaceae). Oecologia 146:394-403. doi:10.1007/s00442005-0217-y

Linhart YB, Feinsinger P (1980) Plant-hummingbird interactions: effects of island size and degree of specialization on pollination. J Ecol 68:745-760. doi:10.2307/2259454

Mayfield MM, Waser NM, Price MV (2001) Exploring the "most effective pollinator principle" with complex flowers: bumblebees and Ipomopsis aggregata. Ann Bot 88:591-596. doi: 10.1006/anbo.2001.1500

Molina-Borja M (1985) Spatial and temporal behavior of Gallotia galloti in a natural population of Tenerife. Bonn Zool Beitr 36:541-552

Ne'eman G, Jürgens A, Newstrom-Lloyd L, Potts SG, Dafni A (2010) A framework for comparing pollinator performance: effectiveness and efficiency. Biol Rev 85:435-451. doi: 10.1111/j.1469-185X.2009.00108.x

Ness JH, Morris WF, Bronstein JL (2006) Integrating quality and quantity of mutualistic service to contrast ant species protecting Ferocactus wislizeni. Ecology 87:912-921. doi:10.1890/00129658872.0 .2

Olesen JM (1985) The Macaronesian bird-flower element and its relation to bird and bee opportunists. Bot J Linn Soc 91:395-414. doi:10.1111/j.1095-8339.1985.tb01010.x

Olesen JM, Jordano P (2002) Geographic patterns in plant-pollinator mutualistic networks. Ecology 83:2416-2424. doi:10.2307/307 1803

Olesen JM, Valido A (2003) Lizards as pollinators and seed dispersers: an island phenomenon. Trends Ecol Evol 18: 177-181. doi:10.1016/S0169-5347(03)00004-1

Olesen JM, Valido A (2004) Lizards and birds as generalized pollinators and seed dispersers of island plants. In: FernándezPalacios JM, Morici C (eds) Ecología insular/island ecology. Asociación Española de Ecología Terrestre (AEET) and Cabildo Insular de La Palma, Madrid, pp 229-249

Olesen JM, Bascompte J, Dupont YL, Jordano P (2007) The modularity of pollination networks. Proc Natl Acad Sci USA 104:19891-19896. doi:10.1073/pnas.0706375104

Ollerton J, Cranmer L, Stelzer RJ, Sullivan S, Chittka L (2009) Bird pollination of Canary Island endemic plants. Naturwissenschaften 96:221-232. doi:10.1007/s00114-008-0467-8

Pough H (1973) Lizard energetics and diet. Ecology 54:837-844. doi: $10.2307 / 1935678$

Primack RB, Silander JA (1975) Measuring relative importance of different pollinators to plants. Nature 255:143-144. doi:10.1038/ 255143a0

R Development Core Team (2011) R: A language and environment for statistical computing, version 2.13.0. R Foundation for Statistical Computing, Vienna. ISBN 3-900051-07-0. http:// www.R-project.org.

Reynolds RJ, Fenster CB (2008) Point and interval estimation of pollinator importance: a study using pollination data of Silene caroliniana. Oecologia 156:325-332. doi:10.1007/s00442008-0982-5

Robertson AW, Ladley JJ, Kelly D (2005) Effectiveness of shorttongued bees as pollinators of apparently ornithophilous New Zealand mistletoes. Aust Ecol 30:298-309. doi:10.1111/j.14429993.2005.01474.x

Rodríguez-Rodríguez MC, Valido A (2008) Opportunistic nectarfeeding birds are effective pollinators of bird-flowers from Canary Islands: experimental evidence from Isoplexis canariensis (Scrophulariaceae). Am J Bot 95:1408-1415. doi:10.3732/ ajb.0800055

Santos A (1990) Bosques de laurisilva en la región macaronésica. Nature and Environmental Series, 49. Council of Europe, Strasbourg

Sazima I, Sazima C, Sazima M (2009) A catch-all leguminous tree: Erythrina velutina visited and pollinated by vertebrates at an oceanic island. Aust J Bot 57:26-30. doi:10.1071/BT08179

Schemske DW, Horvitz CC (1984) Variation among floral visitors in pollination ability: a precondition for mutualism specialization. Science 225:519-521. doi:10.1126/science.225.4661.519

Schueller SK (2004) Self-pollination in island and mainland populations of the introduced hummingbird-pollinated plant, Nicotiana glauca (Solanaceae). Am J Bot 91:672-681. doi:10.3732/ ajb.91.5.672

Schupp EW (1993) Quantity, quality and the effectiveness of seed dispersal by animals. Vegetatio 107/108:15-29

Schupp EW, Jordano P, Gómez JM (2010) Seed dispersal effectiveness revisited: a conceptual review. New Phytol 188:333-353. doi:10.1111/j.1469-8137.2010.03402.x 
Spears EE (1987) Island and mainland pollination ecology of Centrosema virginianum and Opuntia stricta. J Ecol 75:351-362. doi: $10.2307 / 2260423$

Stebbins GL (1970) Adaptive radiation of reproductive characteristics in angiosperms. I. Pollination mechanisms. Annu Rev Ecol Evol Syst 1:307-326. doi:10.1146/annurev.es.01.110170.001515

Steenhuisen SL, Van der Bank H, Johnson SD (2012) The relative contributions of insect and bird pollinators to outcrossing in an african Protea (Proteaceae). Am J Bot 99:1104-1111. doi: 10.3732/ajb.1100535

Stevens PF (2001 onwards). Angiosperm Phylogeny Website. Version 12, July 2012. http://www.mobot.org/MOBOT/research/APweb/

Tscheulin T, Neokosmidis L, Petanidou T, Settele J (2011) Influence of landscape context on the abundance and diversity of bees in Mediterranean olive groves. Bull Entomol Res 101:557-564. doi:10.1017/S0007485311000149

Valido A, Nogales M (1994) Frugivory and seed dispersal by the lizard Gallotia galloti (Lacertidae) in a xeric habitat of the Canary Islands. Oikos 70:403-411. doi:10.2307/3545778

Valido A, Nogales M (2003) Digestive ecology of two omnivorous Canarian lizard species (Gallotia, Lacertidae). Amphibia-Reptilia 24:331-344. doi:10.1163/156853803322440790

Valido A, Olesen JM (2010) Pollination on islands: examples from the Macaronesian archipelagos. In: Serrano ARM, Borges PAV, Boieiro M, Oromí P (eds) Terrestrial arthropods of Macaronesia.
Biodiversity, ecology and evolution. Sociedade Portuguesa de Entomologia, Lisbon, pp 249-283

Valido A, Dupont YL, Hansen DM (2002) Native birds and insects, and introduced honey bees visiting Echium wildpretii (Boraginaceae) in the Canary Islands. Acta Oecol 23:413-419. doi: 10.1016/S1146-609X(02)01167-0

Vaughton G (1992) Effectiveness of nectarivorous birds and honeybees as pollinators of Banksia spinulosa (Proteaceae). Aust J Ecol 17:43-50. doi:10.1111/j.1442-9993.1992.tb00779.x

Vázquez DP, Morris WF, Jordano P (2005) Interaction frequency as a surrogate for the total effect of animal mutualists on plants. Ecol Lett 8:1088-1094. doi:10.1111/j.1461-0248.2005.00810.x

Vogel S, Westerkamp C, Thiel B, Gessner K (1984) Ornithophilie auf den Canarischen Inseln. Plant Syst Evol 146:225-248. doi: 10.1007/BF00989548

Waser NM, Price MV (1990) Pollination efficiency and effectiveness of bumble bees and hummingbirds visiting Delphinium nelsonii. Collect Bot 19:9-20

Waser NM, Chittka L, Price M, Williams NM, Ollerton J (1996) Generalization in pollination systems, and why it matters. Ecology 77:1043-1060. doi:10.2307/2265575

Zamora R (2000) Functional equivalence in plant-animal interactions: ecological and evolutionary consequences. Oikos 88:442-447. doi:10.1034/j.1600-0706.2000.880222.x 